\title{
Representaciones sobre la Independencia de las Provincias Unidas de Sudamérica en Tucumán a finales del siglo XIX*
}

\section{Resumen}

El presente trabajo explora las representaciones sobre la Independencia argentina a partir de las celebraciones impulsadas por asociaciones culturales, estudiantes secundarios y universitarios a fines del siglo XIX. La hipótesis que guía esta investigación sostiene que estos festejos patrios organizados desde la sociedad civil -en particular, las peregrinaciones patrióticas de la juventud llevadas a cabo durante la década de 1890 - se instalaron como prácticas y fueron articulándose con acciones desplegadas por el poder político tendientes a construir una memoria colectiva homogénea sobre los orígenes de la nacionalidad, convirtiendo al recinto donde se declaró la Independencia en capital simbólico que permitió la proyección nacional de Tucumán. La metodología aplicada a la investigación conjuga el análisis de fuentes primarias (documentos oficiales de gobierno, prensa periódica, libros de actas de asociaciones) junto con fuentes editadas como revistas culturales del período y memorias publicadas, lo que permitió establecer un diálogo con la bibliografía especializada.

\section{Palabras clave}

Tesauro: independencia, representación, peregrinación.

Autor: Tucumán, siglo XIX.

Referencia bibliográfica para citar este artículo: Vignoli, Marcela. "Representaciones sobre la Independencia de las Provincias Unidas de Sudamérica en Tucumán a finales del siglo XIX”. Anuario de Historia Regional y de las Fronteras 24.1 (2019): 83-104.

Marcela Vignoli: doctora en Humanidades por la Universidad Nacional de Tucumán, Argentina, realizó su estancia posdoctoral en la Universidad de San Pablo, Brasil (2011) y en la Ohio State University, Estados Unidos (2017-2018). Es investigadora asistente del CONICET y docente de Metodología de la Investigación Histórica de la Universidad Nacional de Tucumán, Argentina. Código ORCID: 0000-00034192-8019. Correo electrónico: vigmarce@gmail.com.

\footnotetext{
${ }^{*}$ La presente investigación fue realizada en el marco del proyecto PICT 2014-0754 financiado por la Agencia Nacional de Promoción Científica y Tecnológica. Lugar de trabajo: Instituto Superior de Estudios Sociales (UNT-CONICET).
} 


\title{
Representations on the Independence of the United Provinces of South America in the Cultural Tucumán at the End of the Nineteenth Century
}

\begin{abstract}
This paper explores the representations about Argentine Independence from the celebrations promoted by cultural associations, secondary and university students at the end of the nineteenth century. The hypothesis that guides this research argues that these patriotic celebrations organised by the civil society-particularly the patriotic pilgrimages of the youth carried out during the decade of 1890 's-were installed as practices and articulated with actions deployed by the political power tending to build a collective homogeneous memory about the origins of nationality, converting the precinct where independence was declared a symbolic capital which allowed the national projection of Tucumán. The methodology applied to research combines the analysis of primary sources (official government documents, periodical press, and record books of associations) along with sources edited as cultural journals of the period and published reports, which enabled to establish a dialogue with the specialised bibliography.
\end{abstract}

Keywords

Thesaurus: Independence, Representation, Pilgrimage.

Author's keywords: Tucumán, 19th Century.

\section{Representações sobre a Independência das Províncias Unidas da América do Sul no Tucumán cultural do final do século XIX}

\begin{abstract}
Resumo
O presente trabalho explora as representações sobre a independência argentina a partir das comemorações promovidas por associações culturais, secundárias e universitárias no final do século XIX. A hipótese orientadora desta pesquisa argumenta que essas celebrações patrióticas organizadas a partir da sociedade civil -particularmente, as peregrinações patrióticas da juventude realizadas durante a década de 1890- foram instaladas como práticas e articuladas com ações realizadas pelo poder político com a tendência a construir uma memória coletiva homogênea sobre as origens da nacionalidade, convertendo o recinto onde a Independência foi declarada capital simbólica que permitiu a projeção nacional de Tucumán. A metodologia aplicada à pesquisa combina a análise de fontes primárias (documentos oficiais do governo, jornais periódicos, livros de cadastro de associações) junto com fontes editadas como periódicos culturais do período e relatórios publicados, o que permitiu estabelecer um diálogo com a bibliografia especializada.
\end{abstract}

Palavras-chave

Tesauro: independência, representação, peregrinação.

Palavras-chave do autor: Tucumán, Século XIX. 


\section{Introducción}

En el último cuarto del siglo XIX la sociedad argentina fue testigo de una expansión de experiencias asociativas de índole cultural-educativa que convocó sobre todo a jóvenes alumnos o egresados de establecimientos educativos nacionales de distintas geografías provinciales, así como estudiantes universitarios de Córdoba y Buenos Aires. Una de las características de este asociacionismo que la historiografía argentina ha caracterizado como "efímero" y "disperso", fue que entre sus variadas inquietudes la evocación patriótica ocupó un lugar relevante, llegando en algunos casos a constituir el principal motivo aglutinante. ${ }^{1}$

El interés por desarrollar esta veta patriótica manifestado por la juventud que circulaba por asociaciones con perfiles culturales se articuló con propósitos del Estado por extender y fomentar valores identitarios entre una sociedad que recibía una gran cantidad de inmigrantes. De ese modo, fechas emblemáticas del pasado argentino sirvieron al tiempo que, para conmemorar, para cimentar una cultura cívica en la población, en la que se debía inculcar valores argentinos. ${ }^{2}$

\footnotetext{
${ }^{1}$ Un panorama sobre asociaciones de índole literario se puede consultar en "Sociedades literarias argentinas existentes entre 1864 y 1900", Seminario que se llevó a cabo en la Universidad de La Plata en 1965 (Sociedades, 1967). Respecto de los vínculos que se entablaron entre estudiantes universitarios, Susana García ha contemplado la creación de redes nacionales e internacionales a partir de los congresos internacionales de estudiantes llevados a cabo durante la primera década del siglo XX (Susana García, "Embajadores intelectuales. El apoyo del Estado a los congresos de estudiantes americanos a principios del siglo XX”, Estudios Sociales 19. 1 (2000): 65-84. Por su parte, Liliana Bertoni destacó la expansión de "asociaciones patrióticas de la juventud" que tuvo lugar durante la década del 1890 en nuestro país, considerando que este fenómeno fue estimulado por la enseñanza de la historia en los colegios. Para la autora, estos espacios se ocupaban de recordar los aniversarios del prócer inspirador, colocaban placas conmemorativas y realizaban homenajes públicos Liliana Bertoni, Patriotas, Cosmopolitas y Nacionalistas: la construcción de la nacionalidad argentina a fines del siglo XIX (Buenos Aires, Fondo de Cultura Económica, 2001). "Sociabilidad estudiantil", es una expresión que a Pilar González Bernaldo le permitió explicar este fenómeno que durante las dos últimas décadas del siglo XIX se multiplicó en la Argentina en íntima asociación con la expansión de establecimientos educativos nacionales, tanto secundarios como universitarios Pilar González Bernaldo, Civilidad y politica en los orígenes de la nación argentina. La sociabilidad en Buenos Aires, 1829-1862 (Buenos Aires: Fondo de Cultura Económica, 2001). Hilda Sábato, a su vez, también llamó la atención sobre la existencia de asociaciones más efímeras aún, como comisiones y comités con fines específicos, por ejemplo, homenajear una figura pública, erigir estatuas y monumentos, o recaudar fondos para alguna causa Hilda Sábato, La política en las calles. Entre el voto y la movilización, Buenos Aires 1862-1880 (Buenos Aires: Universidad Nacional de Quilmes, 2004). Además, debemos mencionar los trabajos de Paula Bruno sobre asociaciones con perfil literario en Buenos Aires durante el periodo Paula Bruno (Dir.), Sociabilidades y vida cultural. Buenos Aires, 1860-1930 (Bernal: Universidad Nacional de Quilmes, 2014). Marcela Vignoli, por su parte, analizó la conformación de un ambiente de sociabilidad cultural en Tucumán a partir de asociaciones creadas por alumnos, egresados y maestros de establecimientos educativos nacionales. Marcela Vignoli, Sociabilidad y cultura política: la Sociedad Sarmiento de Tucumán, 1880-1914 (Rosario: prohistoria, 2015).

${ }^{2}$ De acuerdo con el relevamiento de fuentes realizado, los presupuestos anuales nos informan sobre el dinero que el gobierno destinada a los festejos cívicos. Cuando se comienzan a registrar los presupuestos, lo que se destinaba a los eventos patrios (que lamentablemente no están discriminados por festejo) constituía entre un $1 \%$ y un $3 \%$ del presupuesto oficial anual 1850 y 1870 . Si lo comparamos con otros rubros de la época como podría ser la banda de música por ejemplo constatamos que el porcentaje que el gobierno destinaba a los festejos cívicos en general era bastante alto. Por ejemplo, para el año 1860 el gobierno destinó a festejos cívicos 1500 pesos, mientras que a la banda de música (que incluía desde sueldos a compra o arreglo de
} 
El propósito que persigue esta investigación es analizar el proceso a partir del cual el recinto en el que se había declarado la "Independencia de las Provincias Unidas de Sudamérica" se transformó durante la década de 1890 en un símbolo de la nacionalidad argentina. ${ }^{3}$

En la provincia de Tucumán durante gran parte del siglo XIX las conmemoraciones de la Independencia tuvieron un lugar relevante para aquellos gobiernos que las percibieron como una expresión de apoyo a las autoridades y un indicio de cohesión social tan necesaria durante las primeras décadas del siglo XIX, “[...] como las contribuciones económicas y los enrolamientos militares". ${ }^{4}$ Durante ese periodo, las conmemoraciones fueron impulsadas por alguna figura pública (generalmente gobernadores), todavía espasmódicas rara vez se llevaron a cabo en el inmueble en el que se había declarado la Independencia. ${ }^{5}$

A partir de las dos últimas décadas del siglo XIX comienzan a modificarse una serie de prácticas en torno a estas conmemoraciones lo que dará como resultado representaciones novedosas sobre la Independencia. Una de las hipótesis de este trabajo postula que en este fenómeno tendrá gran incidencia el ingreso de nuevos actores que, a partir de habilidades obtenidas en su paso por el sistema educativo, comienzan a ocupar un lugar expectante en el espacio público lo que potencian con su

instrumentos y trajes) otorgó $\$ 1400$ pesos. Ahora bien, si tomamos el periodo siguiente hasta la primera década del siglo XX, vemos que la inversión en este rubro es notoriamente más baja (llegando en algunos casos a insumir un $0.20 \%$ del presupuesto anual). Esto quizás pueda explicarse por un incremento de la participación de la sociedad civil en la organización de los festejos apelando a suscripciones públicas, a donaciones de particulares, pero también a parte de las subvenciones que recibieron algunas asociaciones con perfil patriótico durante el periodo. Además, por esta época el rubro educación comienza a manejar un presupuesto propio desglosado del anual general, por lo que es muy probable que la esfera educativa tuviera a su cargo la organización de estos eventos. Compilación ordenada de leyes, decretos y mensajes de la Provincia de Tucumán que comienza en 1852, Tomo III y IV (Tucumán: Gobierno de la provincia de Tucumán, 1915).

${ }^{3}$ El 9 de julio de 1816, un Congreso reunido en San Miguel de Tucumán declaro la "Independencia de las Provincias Unidas de Sudamérica" fecha que luego quedo instituida como de la Independencia Argentina.

${ }^{4}$ Ana Cristina Wilde, "Representaciones de la política revolucionaria. Un acercamiento a la liturgia republicana (1810-1853)", Gabriela Tío Vallejo, La república extraordinaria. Tucumán en la primera mitad del siglo XIX (Rosario: Prohistoria, 2011) 87.

${ }^{5}$ De acuerdo con lo relevado en el Archivo Histórico de la Provincia de Tucumán, las conmemoraciones por la Independencia fueron esporádicas durante la primera mitad del siglo XIX. Los festejos por la Independencia comenzaron a realizarse en 1824 y se repitieron en 1831, 1834, 1840, 1846, 1854, 1860, $1861,1872,1974,1876,1877,1878$. Recién a partir de 1880 la correspondiente misa y Tedeum se llevaría a cabo de manera ininterrumpida. La organización partía por lo general de un decreto del Gobernador de turno, excepto en 1854 en que estuvo a cargo de Manuel Posse, comandante General de Caballería. En 1846, bajo el gobierno de Celedonio Gutiérrez se dio la particularidad que la invitación alcanzó también a los empleados del Estado, aunque no podemos determinar si la concurrencia fue obligatoria. En 1881, el decreto alcanzó además a las corporaciones civiles, religiosas, empleados nacionales y cónsules. En 1878 y en 1888, bajo los gobiernos de Federico Helguera y Lídoro Quinteros respectivamente, la conmemoración además de consistir en Misa y Tedeum en la Iglesia Matriz tuvo lugar en la Casa donde se había declarado la Independencia. Será recién a partir de 1892 y a lo largo de todo el periodo bajo estudio ininterrumpidamente, que el festejo incluirá la visita a esta propiedad. Archivo Histórico de Tucumán (en adelante AHT), “Sección administrativa”, vols. 21-184, 1824-1892. 
participación en ámbitos de sociabilidad de índole cultural a partir de $1880 .{ }^{6}$ Producto de la intervención de esta juventud y la asociación con jóvenes universitarios del país, a partir de la década de 1890 las conmemoraciones trascienden el ámbito local. Al respecto, otra de las hipótesis de esta investigación sostiene que el recinto donde había sido declarada la Independencia se convierte en capital simbólico para la proyección nacional de la provincia, logrando ubicar en la conciencia colectiva nacional la idea de Tucumán como origen de la patria. Esto habría tenido tres efectos que también serán analizados en este artículo. Uno inmediato y vinculado a la política provincial, ya que aquel rol central que se le asignaba a Tucumán en el nacimiento del Estado independiente sería utilizado para legitimar a la elite que dirigía la provincia y que pretendía posicionarse como un centro preponderante del norte argentino en los ámbitos de la cultura, la política y la economía. El otro, fue la necesidad de proteger la Casa Histórica, tarea que se encomendó a la Sociedad Sarmiento, lo que terminó por convertirla en mediadora y beneficiaria de ese proceso de legitimización. Por último, es importante destacar, además que, a partir de 1892, a la evocación de la Independencia se suma la de la Batalla de Tucumán, el 24 de septiembre, ${ }^{7}$ de modo que la década de 1890 fija un calendario patriótico que, a modo de liturgia, no dependerá ya de la decisión de las esferas de poder para su conmemoración, recuerdo o festejo.

Para la realización de este trabajo hemos recurrido a distintos tipos de fuentes. Por una parte, relevamos los documentos oficiales del Gobierno de la Provincia de Tucumán a lo largo del siglo XIX para constatar, por una parte, la manera en que se organizaron los festejos patrios, que sectores fueron invitados o bien constreñidos a participar y bajo qué argumentos, y, por otra, los recursos materiales que destinaron las administraciones provinciales a este rubro. Consideramos que los presupuestos provinciales, que rara vez se han utilizado para analizar la inversión gubernamental en este tipo de festejos, permiten reconstruir una época en la que no existía aun una esfera que se ocupara de la cultura. Además, hemos trabajado con los papeles de la Sociedad Sarmiento compuestos por libros de actas de asambleas y de comisión directiva, así como registros de socios, y las revistas literarias que editaba la asociación. Estos documentos permitieron identificar discursos de los socios en los que se advierte el impulso por privilegiar el desarrollo de una pauta patriótica entre la batería de actividades que desplegaba la asociación. Además, hemos ubicado algunos testimonios de la época que fueron posteriormente editados, y que nos

\footnotetext{
${ }^{6}$ Nos referimos principalmente al grupo de socios de la Sociedad Sarmiento, asociación literaria creada en 1882 por alumnos, egresados y maestros de la Escuela Normal (1875) y el Colegio Nacional (1865) de la ciudad de San Miguel de Tucumán. A medida que aumentó la membrecía, se comenzaron a diversificar estas inquietudes literarias hasta abarcar una amplia variedad de tópicos, algunos de los cuales lograron concretarse en acciones específicas. En efecto, la creación de una biblioteca en 1883, de una escuela nocturna para obreros al año siguiente y la edición de dos publicaciones El Porvenir (1882-1883) y El Tucumán Literario (1888-1896) fueron algunos de los proyectos que llevaron adelante los miembros de esta asociación durante su primera década de vida. Como dijimos, en este trabajo destacaremos el papel de esta juventud en la inculcación de una conciencia cívica en la sociedad a través de la incorporación de una pauta patriótica entre sus inquietudes.

${ }^{7}$ El 24 de septiembre el ejército patriota al mando del Gral. Manuel Belgrano derrotó en las puertas de la ciudad de Tucumán al ejército realista en manos de Pío Tristán, frenando una serie de derrotas que amenazaban seriamente el destino de la Revolución en el Río de la Plata.
} 
permiten realizar una reconstrucción del clima de época y las expectativas de muchos de los jóvenes que participaron de este proceso. Por último, la prensa de la época, el periódico "El Orden", nos devela las distintas facciones políticas en la coyuntura específica de la década de 1890, sus posiciones en pugna y el aprovechamiento de estos eventos patrios.

El trabajo está estructurado en torno a tres apartados. En primer lugar, analizaremos la historiografía que se ha ocupado de las fiestas mayas y julias. Constatamos una extensa bibliografía respecto de las celebraciones y conmemoraciones en las "fiestas mayas" en Buenos Aires y algunas otras geografías provinciales, lo que contrasta con los estudios acerca del 9 de julio y sus conmemoraciones. Esto nos invita a reflexionar en la dificultad que han tenido las investigaciones para trascender el ámbito local, e incluso el espacio físico en el que se declaró la Independencia, que constituyó durante gran parte del siglo pasado en un tema recurrente para los estudiosos tucumanos. El segundo apartado, que nos permite entrar en tema específico de esta investigación, se centra en dilucidar el cambio que se dio en torno a la Casa Histórica que pasó de ser un espacio destinado a diferentes áreas de gobierno, hasta convertirse en un lugar de conmemoración patriótica. Finalmente, el último apartado analiza los festejos patrios que se llevaron a cabo durante la década de 1890 que fueron las "peregrinaciones patrióticas de la juventud" en las que participaron diferentes actores de orígenes sociales dispares, y que dieron sustento a ese nuevo estatus que adquiría el recinto en que se había declarado la Independencia de las provincias unidas de Sudamérica.

\section{Los festejos patrios en perspectiva histórica: fiestas mayas y julias}

El estudio de las fiestas cívico-patrióticas, en particular las denominadas "fiestas mayas" ha llamado la atención de historiadores interesados por estudiar la dimensión simbólica de los factores identitarios entre la población. Influenciados por la historiografía francesa, que a partir del análisis de los festejos y simbología cívica patriótica ${ }^{9}$ discutió el bicentenario de 1879 la revolución francesa y la memoria como objeto de estudio, podemos ubicar a estos estudiosos de nuestro medio quienes aproximadamente desde fines del siglo pasado comenzaron a publicar trabajos

\footnotetext{
${ }^{8}$ Durante la última década del siglo XIX estudiantes secundarios y universitarios de Buenos Aires y Córdoba organizaron una serie de viajes que recorrían diversos escenarios que por su carga simbólica despertaban sentimientos patrióticos en los argentinos y aportaban elementos para construir una memoria histórica necesaria para inculcar valores cívicos. En 1891 se trasladaron a Mendoza, en 1893 se movilizaron en Buenos Aires y se trasladaron a Tucumán, en 1894 fueron a Salta, en 1895 volverían a Tucumán, repitiéndose en 1898. Otros lugares elegidos fueron, el Convento de San Lorenzo, Yapeyú y Rosario (Bertoni). Estos paseos recibieron el nombre de "peregrinaciones patrióticas de la juventud". Hemos consultado un diccionario de la época para comprender el significado que los contemporáneos daban al término peregrinación y determinar la interesante asimilación en el lenguaje de prácticas religiosas a cívicas y patrióticas. De acuerdo a esta consulta se trataba de un "[...] viaje que se hace a un santuario por devoción o por voto" Diccionario Enciclopédico Hispano-Americano de Literatura, ciencias, Artes, Etc. (España: Montaner y Simón, 1912). T. XVI, 93.

${ }^{9}$ Mona Ozouf, "La Fête sous la révolution française”, Jacques Le Goff y Nora Pierre, Faire de L'Histoire. T. III, « Nouveau Objets » (París: Gallimard, 1974) 256-277.
} 
pioneros sobre estos tópicos. ${ }^{10}$ Hace algunos años, a este interés se sumó una reflexión respecto del lugar que ocuparon distintos actores en el festejo centenario de 1910, en particular obreros, mujeres e inmigrantes, buscando proyectarse (en algunos casos) a los sentidos que imprimió el gobierno de Cristina Fernández de Kirchner a las conmemoraciones de $2010^{11}$. De modo que el 25 de mayo de 1810 , ya sea que nos estemos refiriendo al proceso revolucionario en el contexto hispanoamericano, el análisis del Centenario de la Revolución de Mayo o a la reflexión de los recientes festejos bicentenario, se convirtió en un tópico que enriqueció debates de diverso tipo.

En efecto, su discusión permitió explicar desde la "invención de una representación colectiva", ${ }^{12}$ en la que convivieron aspectos novedosos con elementos de continuidad con el pasado colonial, lo cual facilitó el nacimiento de "representaciones sociales nuevas muy ricas de significado", ${ }^{13}$ hasta analizar los distintos matices que imprimió el gobierno mencionado a la redefinición del festejo popular en torno a esta fecha.

Por su parte, las representaciones sobre la Independencia concitaron la atención de estudiosos que se centraron en dos cuestiones. Por una parte a partir de la segunda mitad del siglo XX, hubo un interés en explorar el lugar físico donde se firmó la Independencia, es decir la "Casa Histórica" incentivo una serie

\footnotetext{
${ }^{10}$ María Munilla Lacasa, "Celebrar en Buenos Aires. Fiestas patrias, arte y política entre 1810 y $1830 "$, AAVV, El arte entre lo privado y lo público: VI Jornadas de teoría e historia de las Artes (Buenos Aires: CAIA, 1995); Ricardo Salvatore, "Fiestas federales: representaciones de la república en el Buenos Aires rosista", Entrepasados 11, Buenos Aires, (1997): 45-68; Juan Carlos Garavaglia, "A la nación por la fiesta: las fiestas mayas en el origen de la nación en el plata", Boletín del Instituto de Historia y Argentina "Dr. Emilio Ravignani” 22, Buenos Aires, (2000): 73-100.

${ }^{11}$ Ana Laura Lanteri, "Una nacionalidad en consolidación y una ciudad en construcción. Festejos patrios en las primeras décadas de Mar del Plata”, Quinto sol 13, Universidad Nacional de La Pampa, (2009): 105-123; Juan Suriano, "Los festejos del primer Centenario de la Revolución de Mayo y la exclusión del movimiento obrero", Revista de Trabajo 8, Buenos Aires, (2010): 19-27; Gustavo Contreras y otros, La clase obrera y el centenario, 1910 (Buenos Aires: CTA ediciones, 2011). Héctor Recalde (comp.), Señoras, universitarias y mujeres (1910-2010), La cuestión femenina entre el centenario y el bicentenario de la Revolución de Mayo (Buenos Aires: Grupo Editor Universitario, 2010); Miguel De Asúa, "La fiesta de la ciencia", Academia Nacional de Ciencias de Buenos Aires 125. 21 (2011): 18-24; Georgina Gluzman, "El trabajo recompensado: mujeres, artes y movimientos femeninos en la Buenos Aires de entresiglos", Artelogie 5, Buenos Aires (2013): 1-22. Mirta Zaida Lobato, "Conmemoraciones patrióticas y mujeres: los desafíos del presente en el bicentenario de la Revolución de Mayo", Mora 16, (2010): 162-165. Primer Congreso Femenino Internacional de la República Argentina, Buenos Aires, Ceppi, 1911; Jaqueline Vasallo (coord.), Las mujeres en el relato histórico del Centenario (Argentina, 1910) (Argentina: Universidad Nacional de Córdoba, Facultad de Filosofía y Humanidades, 2013); Jaqueline Vasallo (coord.), Señoras patriotas ¿o reacción oligárquica? Actas del Primer Congreso Patriótico de Señoras en América del Sud, 1910 (Argentina: Universidad Nacional de Córdoba, 2012). Pablo Ortemberg, "El Tedeum en el ritual político: usos y sentidos de un dispositivo de pactos en la América española y en la revolución de Mayo", Anuario del Instituto de Historia Argentina 10 (2010): 199-226. http://www.fuentesmemoria.fahce.unlp.edu.ar/art_revistas/pr. 4704/pr.4704.pdf (10/05/2018); Alejandro Eujanian y otros, Episodios de la cultura histórica argentina. Celebraciones, imágenes y representaciones del pasado siglos XIX y XX (Buenos Aires: Biblos, 2015).

${ }^{12}$ Garavaglia 75.

${ }^{13}$ El Tedeum, según Pablo Ortemberg, constituyó (además de los juramentos de lealtad) “[...] uno de los lenguajes disponibles para la construcción ritual de la nueva autoridad suprema, hacer visibles las jerarquías y confirmar antiguos y nuevos pactos", Ortemberg, 97 y 216.
} 
de investigaciones, debates y artículos periodísticos que describieron de manera detallada el derrotero que siguió esta propiedad: así las instancias de alquiler, venta de este inmueble al Estado así como las sucesivas modificaciones administrativas, arquitectónicas y museográficas que atravesó la propiedad fueron en efecto objeto de estudios minuciosos. ${ }^{14}$ Por otra parte, otro de los temas explorados por investigadores de nuestro medio lo constituyen la conmemoración del Centenario de la Independencia en $1916^{15}$. Estas investigaciones analizan los festejos que el gobierno provincial llevo adelante.

La investigación de Soledad Martínez Zuccardi es particularmente relevante para esta investigación ya que a través del análisis de una publicación que reuniría escritos de diversa índole acerca de la provincia y de la región-Tucumán al través de la historia. El Tucumán de los poetas (1916) - la autora reflexiona sobre la encarnación de un discurso respecto de la provincia en aquella conmemoración. Según la autora "Es posible conjeturar que a partir de la realización de una compilación histórica de escritos acerca de Tucumán se aspiraba a fundar la provincia en el plano simbólico, a forjar una memoria local y cimentar una tradición"16. Creemos que este proyecto, que la autora ubica en 1916, comienza mucho antes, alrededor de la última década del siglo XIX, y que además es un proyecto que logra expresar diferentes intereses, por una parte, el Estado (tanto en su esfera nacional como provincial) que, junto a distintos actores de la sociedad civil, coinciden en cimentar una conciencia cívica y patriótica en la población.

\section{El recinto donde se firmó la Independencia: construcción de un símbolo de la nacionalidad argentina}

Como mencionamos las celebraciones por la declaración de la Independencia fueron habituales a lo largo del siglo XIX en la ciudad de Tucumán. Organizadas por las administraciones provinciales constaban de una misa y tedeum en la Iglesia Matriz. A estos actos más bien solemnes se sumaron otras formas de festejo que tuvieron lugar de manera más espasmódica, los bailes patrios.

\footnotetext{
${ }^{14}$ Roberto Zavalía Matienzo, La casa de Tucumán. Historia de la Casa de la Independencia, Tucumán, Archivo Histórico de Tucumán, 1969; Ramón Leoni Pinto, "Notas y rectificaciones sobre la Casa de Tucumán", Revista de la Junta de Estudios Históricos de Tucumán 4 (1974); Lizondo Borda; Carlos Páez de la Torre, La Casa Histórica a través de los años (Tucumán: Edición del autor, 1986); Museo Casa Histórica de la Independencia, La casa de la Independencia, imágenes de ayer y de hoy (Argentina: Tucumán, 1988). Manuel Lizondo Borda, Guía ilustrativa de la Casa Histórica de la Independencia Argentina (Argentina: Gobierno de la Provincia de Tucumán, 1980); Juan Carlos Marinsalda, "La Casa histórica de la Independencia de 1816 y la reconstrucción de Mario J. Buschiazzo", Anales del Instituto de arte americano e investigaciones estéticas Mario J. Buschiazzo 31-32 (Buenos Aires: Universidad de Buenos Aires, 1996-1997) 107-127.

${ }^{15}$ Elena Perilli de Colombres Garmendia, Tucumán en los dos centenarios (1910-1916) (Tucumán: Centro Cultural Alberto Rougés, 1999); Soledad Martínez Zuccardi, "El Centenario de la Independencia y la construcción de un discurso acerca de Tucumán: proyectos y representaciones”, Prismas 19. 1 (2015): 67-87. Marcela Vignoli y otros, "Institucionalización de la cultura: expresiones, nuevos actores, sociedad y estado, 1870-1916", La cultura, artistas, instituciones, prácticas, coord. Marcela Vignoli (Buenos Aires: Imago Mundi, 2017).

${ }^{16}$ Martínez Zuccardi 67.
} 
Según José Fierro, ya el 21 de julio de 1816 tuvo lugar un baile, que se habría repetido bajo el gobierno de José Manuel Silva en 1828 cuando “[...] al aproximarse el 9 de julio, fue espontáneo (sic.) y general el deseo de una solemne recordación" y por lo tanto se consiguió el permiso de la familia Zavalía Laguna para que el baile tuviese lugar en la Casa de la Independencia. Por su parte, en 1858, bajo la gobernación de Marcos Paz se realizó un baile oficial para conmemorar la independencia en el salón de recibos del Cabildo. ${ }^{17}$

Como vemos, a excepción del gobernador Silva, las administraciones provinciales no utilizaron la Casa Histórica como lugar de festejo patrio. Aun cuando a fines de la década de 1860 esta Casa fue adquirida por el gobierno nacional, pasarían varios años hasta que se pensara que este espacio albergaba los sentidos y significados del origen de la nacionalidad argentina.

En 1869, a instancias de un proyecto presentado por el diputado Francisco Padilla que contó con el respaldo de Bartolomé Mitre, el Estado Nacional decidió comprar la casa en la que se había declarado la Independencia a la familia Zavalía Laguna. A partir de esta adquisición, las distintas administraciones, tanto en la esfera nacional como provincial, intentaron destinarla a diversos fines, como el funcionamiento de las oficinas de correos y telégrafos y del juzgado nacional a partir de 1874.

Sin embargo, a fines de la década de 1870 notamos un cambio en la percepción del espacio. En 1878 el gobernador Federico Helguera decidió nombrar a un grupo de jóvenes para que organizaran el festejo. Después del Tedeum, "pueblo y gobierno visitaron la Casa". ${ }^{18}$

A principios de 1880 se pensó que el salón en el que se había efectuado la firma de la declaración de la Independencia podía convertirse en una especie de museo. Para lograrlo el gobierno nacional autorizó al poder local "reunir y colocar los retratos de los ciudadanos que sancionaron la Independencia, sus autógrafos y los documentos emanados de aquella Asamblea a fin de restablecer en cuanto sea posible y conservar esas páginas de una época gloriosa para este país". ${ }^{19}$ La ambientación adecuada a la época de la Independencia se logró mediante la adquisición de muebles antiguos. ${ }^{20}$

Estos decretos encontraron eco en un sector de la sociedad civil ávido por llevar adelante tareas de exaltación patriótica. Como ya adelantamos, se trató del grupo de jóvenes que integraban la Sociedad Sarmiento, quienes a principios de la década de 1890 , decidieron invitar al gobierno provincial a "concurrir a una fiesta literaria,

\footnotetext{
${ }^{17}$ José Fierro, Bailes históricos de Tucumán (Tucumán: Instituto de Estudios Históricos de Tucumán, 1935) $5-7,9,12$.

${ }^{18}$ Lizondo Borda 31.

${ }^{19}$ AHT, "Sección administrativa", vol. 180, tomo II, f. 400.

${ }^{20}$ Zavalía Matienzo.
} 
que en conmemoración del día en que se juró la Independencia argentina, celebrará la Sociedad Sarmiento en el mismo local en que aquel trascendental acontecimiento tuvo lugar", 21

Era una de las primeras veces que se proponía un acto de liturgia patriótica en el sitio en el que en 1816 se había declarado la Independencia de las Provincias Unidas en Sudamérica. Los preparativos habían comenzado en mayo cuando los socios de la Sociedad Sarmiento se dispusieron a ayudar a los vecinos del principal paseo de la ciudad, la Plaza Independencia, a colocar banderas en el exterior de sus casas. Para realizar esta tarea se dividieron en ocho grupos de dos miembros cada uno que se encargaron de embanderar las viviendas. Una de las principales actividades de esta conmemoración consistió en una serie de discursos por parte de los jóvenes miembros de la Asociación. Además de esto, se realizaron misas y se organizó un pequeño desfile por las principales calles de la ciudad. Pero, además del proyectado acto para el 9 de julio, “[...] en asamblea pública celebrada el 25 de mayo se resolvió por unanimidad de votos festejar de manera especial todos los días patrios, contándose también entre estos el 24 de septiembre, aniversario de la Batalla de la Ciudadela en que se decidió la suerte de la revolución argentina $[\ldots]$ ". ${ }^{22}$

Esta decisión, que perseguía el objetivo de expandir las virtudes cívicas y patrióticas entre la población tucumana, aseguraba a los miembros de la Sociedad Sarmiento notoriedad pública lo que les permitiría ocupar un lugar relevante junto a otras asociaciones tradicionales y que contaban ya con una trayectoria destacada en el medio social. $^{23}$

Al año siguiente dando un paso más en ese sentido, la Sociedad Sarmiento publica una solicitada dirigida al "Pueblo de Tucumán",

[...] pidiéndoles tengan a bien engalanar en dicho día el frente de sus respectivos domicilios, con banderas hechas con los colores patrios [...]

A los argentinos patriotas [...] se dirige principalmente este llamativo; al humilde obrero [...] pedímosle también esta manifestación de patriotismo [...] También se dirige este llamado a todos los estrangeros (sic.) sin distinción de nacionalidad $[\ldots]$

Son los miembros de la Sociedad Sarmiento, argentinos en su mayoría que miran en los estrangeros unos colaboradores eficientes del progreso común, los que se dirijen (sic.) a ellos, en prueba de confraternidad, solicitándoles esta muestra de deferencia para su patria cuyo suelo y cielo compartimos por igual $[\ldots] .{ }^{24}$

\footnotetext{
${ }^{21}$ AHT, "Sección administrativa", vol. 196, t. III, f. 150.

${ }^{22}$ La Sociedad Sarmiento y la Unión Universitaria en las fiestas julias (Tucumán: Tipología del bazar argentino, 1893) 3.

${ }^{23}$ Desde la segunda mitad del siglo XIX, una serie de asociaciones nucleaban a la elite económica y política de la provincia. Nos referimos al "Club Julio", que había sido creado en 1857 y al "Club social" fundado en 1875, pero también a la Sociedad de Beneficencia que desde 1858 permitía a las mujeres de la elite tucumana ocupar un rol destacado en tareas de caridad.

${ }^{24}$ Autor. La Sociedad Sarmiento y la Unión Universitaria en las fiestas julias (Tucumán: Tipología del bazar argentino, 1893) 5 .
} 
Era una excelente oportunidad para extender los valores patrióticos entre la sociedad tucumana sin distinciones de clase, ni nacionalidad. No obstante, era también una importante ocasión para que los miembros de la Asociación se presentaran ante la sociedad tucumana mostrando homogeneidad en su composición social y propósitos. El rol que se adjudicaron resultó exitoso cuando una peregrinación patriótica organizada por estudiantes universitarios de Buenos Aires y Córdoba los contactó para organizar en conjunto el festejo patrio de 1893.

\section{Peregrinaciones patrióticas de la juventud durante la década de 1890}

La idea de peregrinar a Tucumán había partido del tucumano Vicente Gallo, Ezequiel Castillo y Miguel Cané, quienes junto con otros estudiantes formaron una comisión que se encargó de planificar las actividades a realizar en el marco de la peregrinación. Incentivados por el fuerte respaldo oficial recibido a través de un subsidio que el Congreso de la Nación sancionó para el pago de pasajes a los estudiantes los que fueron seleccionados por sorteo (Bertoni, 2010: 180), los estudiantes de Buenos Aires y Córdoba comenzaron a proyectaron la peregrinación patriótica a Tucumán y tomaron contacto con los miembros de la Sociedad sarmiento informándoles que a fines de junio iría una comisión para definir el cronograma de los festejos.

La iniciativa contagió al Gobierno de Santiago del Estero, que decidió enviar en el tren en que venían los peregrinos de Córdoba y Buenos Aires a dos batallones infantiles.

En Tucumán, mientras tanto, la Sociedad Sarmiento gestionaba frente a los poderes públicos encargarse de la custodia de los monumentos nacionales. En particular solicitó al "Ministerio del Interior la superintendencia sobre el salón en que se juró la independencia argentina [...] y, a la autoridad respectiva análogo encargo respecto a la estatua del General Belgrano, situada en la Plaza Independencia, como así mismo de la columna conmemorativa de la Batalla de Chacabuco". ${ }^{25}$

La Sociedad Sarmiento, por su parte, gestionó la cooperación del gobierno provincial, que aceptó encargando los retratos de Godoy Cruz, Sánchez Bustamante y Laprida, para ubicarlos en la Casa Histórica. Asimismo, la Asociación recolectó 1.500 pesos por medio de suscripción pública para ornamentar la Casa Histórica y "adornar con arcos, banderas y gallardetes la primera y segunda cuadra de la calle congreso". ${ }^{26}$ Estos arreglos se completaron con una obra del pintor Chiovato, quien, debido al mal estado de la casa original, reprodujo en un lienzo el frente de la fachada del inmueble tal como se conservara desde 1816 hasta 1874.

\footnotetext{
${ }^{25}$ Archivo Biblioteca Sarmiento (en adelante ABS), Sociedad Sarmiento, Tucumán, Libro de Actas, T. II, 20 de abril de 1893, 278.

${ }^{26}$ AHT, Periódico El Orden, (Argentina) 5 de julio de 1893.
} 
Además de las actividades planeadas por la Asociación, la iniciativa de los universitarios imprimía otro color a los festejos, animando a la elite política y económica de la provincia a involucrarse. Por este motivo, comenzaron a organizarse paseos por ingenios y establecimientos de diferentes familias tucumanas como los Nougués y Gallo que abrieron sus puertas para recibir a los estudiantes.

Los miembros de la Sociedad Sarmiento, algunos jóvenes estudiosos de orígenes humildes pero que a través de su paso por el sistema educativo integraban una minoría privilegiada en medio de una sociedad todavía analfabeta, aprovecharían estos eventos de conmemoración patriótica para interactuar junto con diferentes sectores de la élite que se mostraron interesados en participar de estos estos eventos. A pesar de esto, estas actividades continuaban evidenciando las diferencias sociales que se expresaban en la sociedad tucumana. El diario El Orden lo hacía notar de la siguiente manera, "Puede decirse que nunca como en el presente se han hecho tantos preparativos. Todos nos disponemos a divertirnos, cada uno en su esfera, bien en los festejos populares y callejeros, bien en los salones en que se reunirá nuestra mejor sociedad". ${ }^{27}$

Un lugar relevante ocupan los discursos que durante el 9 de julio, tuvieron como oradores a algunos representantes de la Sociedad Sarmiento, así como a alumnos que hablaron en representación de las distintas universidades.

Próspero Mena, quien era entonces presidente de la Sarmiento, hizo alusión al momento refiriendo al "personalismo de los partidos que carcome nuestras instituciones sociales", mientras realzaba la actitud de los estudiantes, quienes "traen el augurio de mejores días que los actuales al porvenir de la patria, siendo el símbolo de la fraternidad argentina", ${ }^{28}$

La ausencia de representantes del gobierno tucumano durante los festejos no paso desapercibida. Al día siguiente de las conmemoraciones, El Orden manifestó: "El gobierno de Tucumán no ha creído de su deber recibir oficialmente a los jóvenes peregrinos. Ha dejado todo a la iniciativa privada, poniendo de manifiesto en día tan solemne su desidia, su impopularidad, su carencia absoluta de patriotismo". ${ }^{29}$ Informaba, también, que el gobernador de la provincia, entonces Próspero García, incluso se había ausentado de la ciudad durante los festejos.

Por el contrario, en 1894, la peregrinación patriótica encontró decidido apoyo en el elenco gobernante y esto se publicó detallando minuciosamente las actividades: Tedeum, entrada a la Casa Histórica y discursos a cargo del vice-gobernador Lucas

\footnotetext{
${ }^{27}$ AHT, Periódico El Orden, (Argentina) 4 de julio de 1893.

${ }^{28}$ AHT, Periódico El Orden, (Argentina) 11 de julio de 1893.

${ }^{29}$ AHT, Periódico El Orden, (Argentina) 10 de julio de 1893.
} 
Córdoba ${ }^{30}$ y del Ministro de Hacienda de la Provincia. Además, aparecían nuevamente las diferencias entre festejos callejeros y los salones de la "mejor sociedad":

En seguida la inmensa concurrencia se dirigía a la Casa de Gobierno donde fue obsequiada con buenos cigarros y licores finos. Al abandonar las oficinas nos encontramos confundidos con las multitudes del pueblo que llenaba todas las avenidas de la plaza, divirtiéndose unos en las calecitas [sic], otros en el palo jabonado y el rompe-cabezas, y los demás en los diversos juegos preparados $a d$ hoc. [...] A las 9 pm. El gobernador acompañado de sus ministros se presentaba en el Teatro Belgrano, donde la compañía de María daba una función de gala en honor del gran día de la patria [...] Al concluir el espectáculo, en los hermosos salones del Club Social se daba principio al espléndido baile anunciado, no decayendo el entusiasmo hasta la madrugada. ${ }^{31}$

El relevante papel que la Sociedad Sarmiento había logrado ocupar en la promoción, diseño y organización de la liturgia patriótica en estrecha relación con el Estado provincial se confirma con una resolución de este último de enero del mismo año, mediante la cual se comprometía a concretar el proyecto (aprobado en 1889) de levantar un monumento en homenaje a Juan Bautista Alberdi y se encomendaba a la Sociedad las gestiones para llevar a cabo la obra. Era evidente que la complementación de la Sarmiento con el Estado provincial en la organización de eventos conmemorativos era muy sólida y muy difícilmente podía desplazársela del centro de la escena en un proyecto tan importante al sentimiento de los tucumanos. Unos meses después se donaban a la Biblioteca de la Sociedad los Escritos póstumos de Juan B. Alberdi. ${ }^{32}$

En 1895 la peregrinación volvió a repetirse a Tucumán, ocasión en la que, en el interior de la Provincia, el Centro Patriótico de Concepción (fundado un año antes) se sumó a los festejos,

Habiéndose despertado en el alma de todos los patriotas y progresistas ciudadanos del pueblo de Concepción el recuerdo de la memorable fecha [...] prepara una fiesta que llenará las aspiraciones de este pueblo [...] Nosotros también no (sic.) queremos permanecer indiferentes y queremos que en nuestra población se celebre con las dulces ideas del patriotismo el día 9 de Julio de 1895.

[...] Estamos convencidos que su poderosa cooperación influirá para dar más realce a nuestros pensamientos y es por eso que venimos a solicitar la Banda de Música o parte de ella. ${ }^{33}$

\footnotetext{
${ }^{30}$ Lucas A. Córdoba, político identificado con el roquismo a nivel provincial, fue vice-gobernador durante la gestión de Benjamín Paz y luego asumió la gobernación en dos oportunidades (1895-1898; 1901-1904). Ambas gestiones se caracterizaron por el fomento a expresiones que, como la música y la pintura, se materializaron en centros dedicados a su estudio y en becas de perfeccionamiento. El caso de la compra de la "Galería de los Gobernadores" a la joven artista Lola Mora en 1894 constituye un destacado ejemplo de las dimensiones que había tomado la cultura en la órbita del Estado.

${ }^{31}$ Hemeroteca de la Facultad de Filosofía y Letras (en adelante HFFyL), Tucumán Literario, 22 de julio de 1894, núm. 18, 149.

${ }^{32}$ AHT, "Sección administrativa", vol. 215, tomo V, 31 de mayo de 1895, 242.

${ }^{33}$ AHT, "Sección administrativa", vol. 216, Tomo VII, 18 de junio de 1895, 95. Al respecto podemos
} 
A la peregrinación de 1895 se sumaron, a los universitarios de Buenos Aires y Córdoba, estudiantes del Colegio Nacional de Buenos Aires y estudiantes de la Escuela Normal de Concepción del Uruguay en la Provincia de Entre Ríos, así como representantes puntanos (San Luis) y santafesinos. Y como en 1894, el gobierno provincial aportó 400 pesos para la realización de los festejos. El espacio dedicado por El Orden es una muestra de la trascendencia que había adquirido la celebración en el medio local. La crónica periodística daba la lista completa de los estudiantes, el nombre de los oradores que representaban a cada delegación y describía cada una de las actividades programadas para el 9 de julio, que excedían ampliamente las realizadas dos años antes.

No faltaron fuegos artificiales, una kermés y una guardia de honor en el Salón de la Independencia. Entre las actividades organizadas para los peregrinos se repetían las visitas a los principales los ingenios azucareros.

Este evento patriótico tuvo una importante repercusión nacional y en la región latinoamericana como quedó demostrado con la edición de postales que recordaron la peregrinación.

Imagen 1: Postal peregrinación patriótica 1898 a la ciudad de Tucumán.

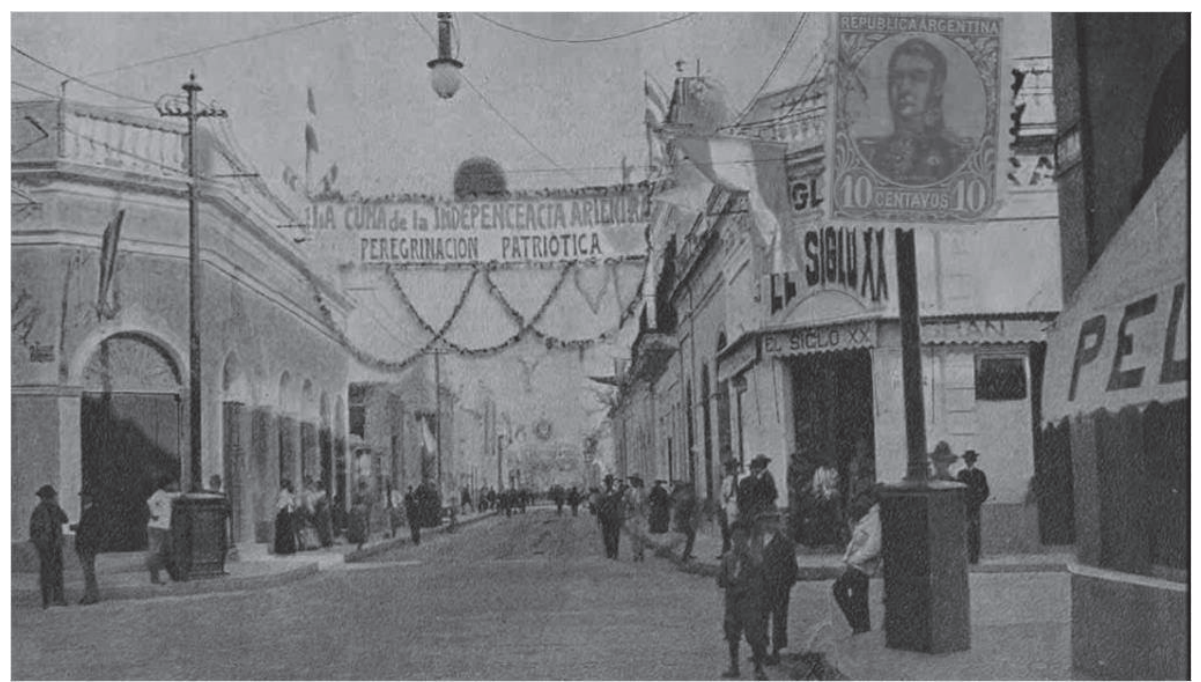

Fuente: Colección privada Muela y Porcel.

agregar que hemos constatado la expansión de asociaciones de índole cultural y bibliotecas populares en el interior tucumano que permitió a localidades remotas incorporar prácticas culturales novedosas al tiempo que asociarse al Estado en los festejos patrios. Vignoli, Sociabilidad y cultura política 41-45. 
Además de la exaltación patriótica y los recorridos por algunos lugares históricos de la provincia, las peregrinaciones significaron para muchos de los jóvenes recién egresados como maestros normales, la posibilidad de vincularse con personas que tenían intereses comunes y que ocupaban lugares clave en el sistema educativo y por lo tanto tenían la posibilidad de ofrecerles oportunidades laborales.

Es lo que ocurrió con Agenor Albornoz, socio de la Sarmiento que en 1895 estuvo encargado de atender a los peregrinos de la Escuela Normal de Concepción del Uruguay. Este maestro diplomado, que en ese momento trabajaba en una de las escuelas de la campaña tucumana, se contactó además con Pedro Alcacer - Ministro de Justicia e Instrucción pública que había venido con los estudiantes de Santa Fe a la peregrinación patriótica-, quien le propuso llevarlo a Santa Fe, donde "[ [...] un gran movimiento educacional se operaba [...] que de toda la República afluían maestros a la provincia, que eran muy bien pagados, que los pagos se hacían al día, que él me garantía una carrera lúcida". Estas promesas no solo convencieron a Albornoz que renunció a su cargo, sino también en tomar la decisión rápidamente "Y me marché en tren expreso con ellos, en busca de mejores bienes, con mi título, unos cuantos libros [...]". ${ }^{34}$

La labor realizada en torno a fomentar el patriotismo entre la población tucumana llevó a uno de los socios a considerar que los objetivos de la Sociedad se habían ampliado o proyectado hacia otros horizontes. Para José Fierro, durante la década de 1890 la Sociedad Sarmiento, "[...] ha tomado otro carácter y durante estos últimos años ha sido una sociedad patriótica. Principió haciendo un llamado al vecindario para el embanderamiento de la ciudad y fue la Sociedad Sarmiento quien inauguró las visitas a la sala de la Independencia". ${ }^{35}$

En 1898 las peregrinaciones volvieron a repetirse en Tucumán. A cargo de la Sociedad Sarmiento, los festejos involucraron ese año a diferentes asociaciones que tuvieron una participación activa en su preparación. Uno de los socios de la Sarmiento, el gallego Paulino Rodríguez Marquina, encargado de redactar un manifiesto que exhortaba a los vecinos a embanderar la ciudad para el evento, reflexionaba en la ocasión: "Esperamos pues que sola o entre las de las diferentes naciones cuyos hijos comparten la tarea de nuestro engrandecimiento, flotará en ese día en todo. Tucumán la bandera azul y blanca, testigo mudo de nuestras glorias". Respondiendo a la invitación cursada por la comisión organizadora se sumaron oficialmente al festejo patrio, entre otras instituciones, las sociedades italiana, francesa, española, suiza y Argentina de Socorros Mutuos; el Comité Italiano de Beneficencia; la Sociedad Fratellanza Militare; El Orfeón Español y Argentino y el Centro Cosmopolita de Obreros. La particularidad de los actos de 1898 estuvo dada por el ingreso de la bandera española por primera vez en el edificio donde sesionó el congreso que declaró la Independencia de "las Provincias Unidas en Sudamérica" de la Corona española.

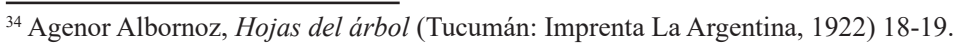

${ }^{35}$ HFFyL Tucumán Literario, (Argentina) 25 de junio de 1896, núm. 42, 429.
} 
Como una muestra de gran compromiso con la luturgia patriótica local, en el evento Paulino Rodríguez Marquina pronunció un discurso en representación de los inmigrantes penisulares radicados en Tucumán y el coro de la Sociedad Española entonó las estrofas del himno nacional argentino. La exaltación de uno de los hitos fundantes de la "Nación argentina" para el imaginario público era sin duda un expresivo y contundente modo de dar a conocer la adopción por parte de una comunidad de residentes extranjeros de sentimientos y valores determinantes desde el punto de vista identitario de la sociedad anfitriona. Pero, si el compromiso con la "patria argentina" llevaba implícito el reconocimiento de deberes, también implicaba una demanda de derechos, entre ellos el de ocupar posiciones prominentes en instituciones de la sociedad civil.

En cuanto a la participación de "la niñez", quedaba claro que su presencia en los actos reafirmaba el propósito general de los festejos, desarrollar un espíritu de ciudadanía y patriotismo, que debía comenzar a forjarse en las más tempranas edades, reforzando los roles tradicionales impuestos a mujeres y varones. Al respecto, luego de los festejos El Orden comentaba: “[...] más de 6.000 niños, futuros ciudadanos y futuras madres de argentinos desfilaron con motivo del aniversario de la Independencia". ${ }^{36}$

Entre 1898 y 1901 la Sociedad Sarmiento asumiría otra importante responsabilidad de gran valor simbólico: se convirtió en la asociación encargada de custodiar la Casa de la Independencia, cuyo estado de conservación había merecido duras críticas por parte de El Orden:

La pared norte del histórico monumento ha sufrido sensibles deterioros con la acción del tiempo, a pesar de algunas refacciones que le hicieron en ella, y las filtraciones de las lluvias, que se producen también en la parte del techo, han ocasionado desprendimientos del reboque (sic) Y no sería extraño que también causaran algún desplome. ${ }^{37}$

Algunos miembros de la Sociedad, que estaban al tanto de la situación, decidieron dirigirse al gobierno nacional solicitando participación en la custodia de la casa, que por esos momentos albergaba la Oficina de Correos y Telégrafos. Según el mismo periódico “[...] los socios de la Sarmiento hacen aquélla petición con el patriótico propósito de asegurar la conservación de la reliquia americana que Tucumán se enorgullece de conservar en su suelo". ${ }^{38}$

Del mismo modo, cuando a principios de 1901 el gobernador Próspero Mena tuvo que decidir en qué manos se depositarían los retratos de los Congresales de 1816 que el gobierno nacional había enviado para ser expuestos en la Casa de la Independencia, encomendó a la Sociedad Sarmiento su custodia, reforzando el

\footnotetext{
${ }^{36}$ AHT, Periódico El Orden, (Argentina) 12 de julio de 1898.

${ }^{37}$ AHT, Periódico El Orden, (Argentina) 9 de marzo de 1898.

${ }^{38}$ AHT, Periódico El Orden, (Argentina) 30 de marzo de 1898.
} 
reconocimiento oficial hacia la Asociación por su labor a favor de la difusión de las tradiciones y la consolidación del sentimiento patrio. La distinción se justificaba con los siguientes términos:

Teniendo en cuenta que la Sociedad Sarmiento, no obstante su índole genuinamente literaria, preside en los días de recordaciones históricas los movimientos populares rememorativos de las efemérides nacionales, me es grato hacerle entrega -en carácter de depósito y para que esa institución los haga colocar todos los aniversarios en la Casa de la Patria- de los retratos de los congresales de 1816, que el Gobierno de la Nación encomendó [...] No dudando que la Sociedad Sarmiento, que tanto se preocupa secundando la acción de los poderes públicos, por mantener en el espíritu del pueblo el culto de las tradiciones nacionales, recibirá como un depósito patriótico los retratos de los próceres [...] (Zavalía Matienzo, 1969: 235).

Como una manera de asegurar una continuidad en estas conmemoraciones en 1906 un socio de la Sarmiento propuso que "la peregrinación patriótica fuera costumbre tradicional y que el poder ejecutivo invite al presidente y sus ministros". ${ }^{39}$

Las actividades descriptas, que buscaban reforzar el sentimiento patriótico en la sociedad tucumana, se complementaban con una serie de competencias y concursos que tenían como objeto promover el estudio y la investigación de temas científicos, literarios e históricos. ${ }^{40}$ Asimismo, también las competencias atléticas y deportivas comenzaron a formar parte importante de los festejos patrios hasta convertirse en una actividad más que se sumaba a los desfiles ó a la visitas a la Casa Histórica de la Independencia. Durante los primeros años del siglo XX, a la tradicional peregrinación del 9 de julio se sumó la participación de ciclistas que acompañaron los festejos con una marcha de antorchas. Los deportistas se nucleaban en un el club de reciente fundación a instancias de José Fierro el 27 de septiembre de 1902, el Club Atlético Tucumán, que celebraba sus reuniones en la sede de la Sociedad.

\section{Consideraciones finales}

A partir de la segunda mitad del siglo XIX el Estado nacional y provincial mostraron un marcado interés por construir una memoria colectiva homogénea sobre los orígenes de la nacionalidad en su propósito por fijar valores por todos compartidos sobre lo argentino. Esto se puede corroborar en el dinero destinado a las fiestas cívicas que se incluían en los presupuestos anuales y que como vimos podían llegar a ser más abultados que otros recursos destinados a expresiones de cultura; en la ayuda extra que recibían los jóvenes peregrinos para sus excursiones a lugares históricos, y,

\footnotetext{
${ }^{39}$ La propuesta fue de Santiago Maciel, socio activo de la Sociedad Sarmiento desde 1885 y que al momento de formular la propuesta era el Intendente General de Policía. AHT, "Sección administrativa", Tomo VIII, vol. 314, 28 de junio de 1906, 227.

${ }^{40}$ Daniel Campi y Marcela Vignoli, "La emergencia de la cuestión social en Tucumán. Un concurso de la Sociedad Sarmiento de 1892”, Nuevos mundos mundos nuevos, (2016). http://journals.openedition.org/ nuevomundo/69361 (23/04/2018), DOI: 10.4000/nuevomundo.69361
} 
además en la participación (y los discursos pronunciados) en estos eventos patrióticos de figuras relevantes vinculadas a la política nacional y provincia. Análisis aparte merecen las personalidades que pertenecían a colonias extranjeras en la provincia y que en estos festejos se mostraron deseosos por asimilarse al patriotismo argentino. Un ejemplo elocuente lo constituye el ingreso de la bandera española en el marco del festejo de 1898 analizado.

Por su parte, algunas asociaciones culturales que nucleaban a estudiantes secundarios y universitarios se identificaron con estas iniciativas estatales posibilitando que estas encarnen en proyectos que resultaron efectivos para tales propósitos. En Tucumán, los jóvenes con inquietudes literarias y culturales rápidamente vieron la oportunidad que ofrecía cimentar los valores cívicos en la población. La apelación a las representaciones sobre la declaración de la Independencia, no solo les permitiría lograr notoriedad en el espacio público y vincularse con personalidades importantes de la cultura y la política nacional.

De este modo, las "peregrinaciones patrióticas de la juventud" -que con gran empeño fueron cuidadosamente organizadas por estos jóvenes con inquietudes culturales- no sólo sirvieron para recrear el pasado histórico, sino también como una manera de legitimar (o poner en cuestión) las situaciones políticas del presente. Por ejemplo, a lo largo de este trabajo vimos como la primera de estas reuniones sirvió para dejar en evidencia la debilidad y el aislamiento del gobierno de Próspero García, mientras que, en años sucesivos, el gobierno participó de la organización de estos eventos, asociándose al éxito de los festejos. Del mismo modo, la protagónica participación de las entidades representativas de la inmigración extranjera perseguía difundir en ellas una identidad argentina y un sentimiento patriótico que sin duda competía o se sobreponía con la natural identificación de los migrantes con su patria de origen.

Junto a la organización de las peregrinaciones estudiantiles y otras actividades que promovían la conformación de un imaginario nacional, la Asociación también se propuso poner de relevancia el rol de los tucumanos en el relato nacional, resaltando el papel jugado por la provincia en las gestas patrias.

Cuando la Sociedad Sarmiento asumió esta tarea vinculada a la extensión del patriotismo fue definiendo un perfil asociativo exitoso que le permitió a corto plazo trascender el ámbito local. A nivel individual, también podemos plantear que el lugar de notoriedad que ocupa la asociación a partir de asumir este rol permitió a alguno de sus socios poner en práctica la capacidad de agencia individual y obtener beneficios personales.

Es interesante destacar que estos actos de liturgia patriótica que se llevaron a cabo en el sitio que en 1816 se había declarado la independencia de "las Provincias Unidas en Sudamérica", terminaron por convertir a la Casa Histórica -que hasta la década de 1870 rara vez había sido utilizada como lugar de festejo- en un símbolo de la nacionalidad argentina. 


\section{Bibliografía}

\section{Fuentes primarias}

\section{Fuentes de archivo}

Archivo Histórico de la Provincia de Tucumán, Tucumán, Fondo de Gobierno, Sección administrativa.

Archivo Biblioteca Sarmiento, Tucumán, Libro de actas.

\section{Prensa}

Archivo Histórico de la Provincia de Tucumán, Tucumán, El Orden, Tucumán, $1893,1895,1898$.

Hemeroteca de la Facultad de Filosofía y Letras (HFFyL) Tucumán, Revista "El Tucumán Literario", 1888-1896.

\section{Fuentes secundarias}

\section{Libros}

Albornoz, Agenor. Hojas del árbol. Tucumán: Imprenta La Argentina, 1922.

Bertoni, Liliana. Patriotas, Cosmopolitas y Nacionalistas: la construcción de la nacionalidad argentina a fines del siglo XIX. Buenos Aires: Fondo de Cultura Económica, 2001.

Bruno, Paula (Dir.). Sociabilidades y vida cultural. Buenos Aires, 1860-1930. Bernal: Universidad Nacional de Quilmes, 2014.

Contreras, Gustavo y otros. La clase obrera y el centenario, 1910. Buenos Aires: CTA ediciones, 2011.

Eujanian, Alejandro y otros. Episodios de la cultura histórica argentina. Celebraciones, imágenes y representaciones del pasado siglos XIX y XX. Buenos Aires: Biblos, 2015 .

Fierro, José. Bailes históricos de Tucumán. Tucumán: Instituto de Estudios Históricos de Tucumán, 1935.

González Bernaldo, Pilar. Civilidad y política en los orígenes de la nación argentina. La sociabilidad en Buenos Aires, 1829-1862. Buenos Aires: Fondo de Cultura Económica, 2001. 
Representaciones sobre la Independencia de las Provincias Unidas de Sudamérica...

Lizondo Borda, Manuel. Guía ilustrativa de la Casa Histórica de la Independencia Argentina. Tucumán: Gobierno de la Provincia de Tucumán, 1980.

Páez de la Torre, Carlos. La Casa Histórica a través de los años. Tucumán: Edición del autor, 1986).

Perilli de Colombres Garmendia, Elena. Tucumán en los dos centenarios (1910-1916). Tucumán: Centro Cultural Alberto Rougés, 1999.

Recalde, Héctor (comp.). Señoras, universitarias y mujeres (1910-2010), La cuestión femenina entre el centenario y el bicentenario de la Revolución de Mayo. Buenos Aires: Grupo Editor Universitario, 2010.

Sábato, Hilda. La política en las calles. Entre el voto y la movilización, Buenos Aires 1862-1880. Bernal: Universidad Nacional de Quilmes, 2004.

Sin autor. Compilación ordenada de leyes, decretos y mensajes de la Provincia de Tucumán que comienza en 1852, Tomo III y IV. Tucumán: Gobierno de la provincia de Tucumán, 1915.

Sin autor. AAVV Diccionario Enciclopédico Hispano-Americano de Literatura, ciencias, Artes, Etc. España: Montaner y Simón, 1912.

Sin autor. La casa de la Independencia, imágenes de ayer y de hoy. Tucumán: Museo Casa Histórica de la Independencia, 1988.

Sin autor. La Sociedad Sarmiento y la Unión Universitaria en las fiestas julias. Tucumán: Tipología del bazar argentino, 1893.

Sin autor. Primer Congreso Femenino Internacional de la República Argentina. Buenos Aires: Ceppi, 1911.

Sin autor. Sociedades Literarias argentinas (1864-1900). La Plata: Universidad Nacional de La Plata, Facultad de humanidades y ciencias de la Educación, 1967.

Vasallo, Jaqueline (Coord.). Las mujeres en el relato histórico del Centenario. Argentina, 1910), (Córdoba: Universidad Nacional de Córdoba, Facultad de Filosofía y Humanidades, 2013.

Vasallo, Jaqueline (Coord.). Señoras patriotas ¿o reacción oligárquica? Actas del Primer Congreso Patriótico de Señoras en América del Sud, 1910. Córdoba: Universidad Nacional de Córdoba, 2012.

Vignoli, Marcela. La cultura en Tucumán. Artistas, instituciones, prácticas. Buenos Aires: Imago Mundi, 2017. 
Vignoli, Marcela. Sociabilidad y cultura politica: la Sociedad Sarmiento de Tucumán, 1880-1914. Rosario: Prohistoria, 2015.

Zavalía Matienzo, Roberto. La casa de Tucumán. Historia de la Casa de la Independencia. Tucumán: Archivo Histórico de Tucumán, 1969.

\section{Capítulos de libros}

Bazán, Raúl Armando. "La región del Noroeste en la Argentina del Centenario" La Generación del Centenario y su proyección en el Noroeste argentino (1900-1950). Tucumán: Centro Cultural Alberto Rougés, Fundación Miguel Lillo, 2000.

Munilla Lacasa, María. “Celebrar en Buenos Aires. Fiestas patrias, arte y política entre 1810 y 1830”, El arte entre lo privado y lo público: VI Jornadas de teoría e historia de las Artes. Buenos Aires: CAIA, 1995.

Ozouf, Mona. "La Fête sous la révolution française", Faire de L'Histoire, T. III, Nouveau Objets. Jacques Le Goff y Pierre Nora, París: Gallimard, 1974.

Vignoli, Marcela y otros, "Institucionalización de la cultura: expresiones, nuevos actores, sociedad y estado, 1870-1916", La cultura, artistas, instituciones, prácticas. Coord. Marcela Vignoli. Buenos Aires: Imago Mundi, 2017.

Wilde, Ana Cristina. "Representaciones de la política revolucionaria. Un acercamiento a la liturgia republicana (1810-1853)", La república extraordinaria. Tucumán en la primera mitad del siglo XIX. Rosario: Prohistoria, 2011.

\section{Artículos de revistas}

Bruno, Paula. "El Círculo literario: un espacio de sociabilidad en la Buenos Aires de la década de 1860". Iberoamericana XV. 59 (2015), 45-63.

Daniel Campi y Marcela Vignoli, "La emergencia de la cuestión social en Tucumán. Un concurso de la Sociedad Sarmiento de 1892", Nuevos mundos mundos nuevos, (2016). http://journals.openedition.org/nuevomundo/69361, DOI: 10.4000/ nuevomundo.69361 (2018).

De Asúa, Miguel. "La fiesta de la ciencia”. Academia Nacional de Ciencias de Buenos Aires 21. 125 (2011): 18-24.

Garavaglia, Juan Carlos. "A la nación por la fiesta: las fiestas mayas en el origen de la nación en el plata". Boletín del Instituto de Historia y Argentina "Dr. Emilio Ravignani” 22 (2000): 73-100.

García, Susana. "Embajadores intelectuales. El apoyo del Estado a los congresos de estudiantes americanos a principios del siglo XX". Estudios Sociales 19 (2000): 65-84. 
Representaciones sobre la Independencia de las Provincias Unidas de Sudamérica...

Gluzman, Georgina. "El trabajo recompensado: mujeres, artes y movimientos femeninos en la Buenos Aires de entresiglos". Artelogie 5 (2013): 1-22.

Lanteri, Ana Laura. "Una nacionalidad en consolidación y una ciudad en construcción. Festejos patrios en las primeras décadas de Mar del Plata”. Quinto sol 13 (2009): 105-123.

Leoni Pinto, Ramón. “Notas y rectificaciones sobre la Casa de Tucumán”. Revista de la Junta de Estudios Históricos de Tucumán 4 (1974).

Lobato, Mirta. "Conmemoraciones patrióticas y mujeres: los desafíos del presente en el bicentenario de la Revolución de Mayo". Mora 16 (2010): 162-165.

Marinsalda, Juan Carlos. "La Casa histórica de la Independencia de 1816 y la reconstrucción de Mario J. Buschiazzo". Anales del Instituto de arte americano e investigaciones estéticas Mario J. Buschiazzo 31-32 (1996-1997): 107-127.

Martínez Zuccardi, Soledad. "El Centenario de la Independencia y la construcción de un discurso acerca de Tucumán: proyectos y representaciones”. Prismas 19. 1 (2015): 67-87.

Ortemberg, Pablo. "El Tedeum en el ritual político: usos y sentidos de un dispositivo de pactos en la América española y en la revolución de Mayo". Anuario del Instituto de Historia Argentina 10 (2010). http://www.fuentesmemoria.fahce.unlp. edu.ar/art_revistas/pr. 4704/pr.4704.pdf, 199-226. (2018)

Perilli, Carmen. "La patria entre naranjos y cañaverales. Tucumán y el primer centenario". Pilquen 12 (2010): 1-9.

Salvatore, Ricardo. "Fiestas federales: representaciones de la república en el Buenos Aires rosista”. Entrepasados 11 (1997): 45-68.

Suriano, Juan. "Los festejos del primer Centenario de la Revolución de Mayo y la exclusión del movimiento obrero". Revista de Trabajo 8 (2010): 19-27. 